\title{
Conclusion: Drawing the Line
}

This work began by posing the question of what the essence of martial arts might be. It has deconstructed this question and this matter in a variety of ways in a journey around some of the regions associated with martial arts. This has neither been a journey to the heart of the matter (as 'heart' in this sense would be a synonym of centre or essence) nor a cartographic journey around a circumference (as this would involve the circumnavigation of a stable territory). If such a journey were possible, then the essence of martial arts could be defined.

Approaching martial arts as a complex, contingent and variable range of discursive constructs in this way can suggest one of at least two possible relationships to the question of 'definition' with which we began, and which has returned in various ways throughout this book. One relation involves accepting the variability of the construct and defining the object, phenomenon or field of practice anyway. Another relation involves accepting the variability of the construct and declining, on that basis, to offer any firm definition, while nonetheless tacitly accepting that martial arts exist, at least as ideas and notions within various discursive and cultural contexts. Both relations have their benefits and drawbacks, as we have seen.

I have argued for the latter. One symptom of this choice may be said to have taken the form of my repeated assertion that martial arts studies researchers ought to move on from the question of defining martial arts in one breath before I have myself returned again and again to the topic in the next. However, my 
fixation on encouraging researchers and writers to get 'past' a certain fixation on defining exists because I believe there are more negative consequences to the fixation on definition than there are positives. Consequently, once more, it seems important to reiterate here the argument about why it is that the question of 'how to define martial arts' is not only a pseudo-problem but also regressive and even potentially damaging for martial arts studies.

Consider it this way. The question of definition (in martial arts studies and elsewhere) involves asking and exploring the question of where to draw the line. When we ask 'What is or are martial arts?', we are asking a specifically focused version of 'Where do we draw the line?' Once asked, the question 'What is or are martial arts?' will become a matter that discussion and debate will become stuck on, or stuck in. This is because there is no universally clinching and uncontestably definitive answer.

While there may be no obviously negative intellectual or even ethical or political consequences associated with arguing about definitions, there are some less obvious ones. As such, in order to avoid this quicksand, in what follows, I want to walk around the trap, reflecting less on 'Where do we draw the line?' and more on 'Why draw the line?' and, indeed, 'How - or in what ways - should anyone draw the line?'

To do this requires reflection on what the act of defining or drawing a line in the first place is or does. Posed directly: What is the line, anyway? What is a definition? What is the need that is being engaged? While there is a very large amount that could be said in response to such questions, in relation to the definition of martial arts, the line that people believe needs to be drawn is a line between 'martial arts' (on one side - the inside) and 'not martial arts' (on the other side - outside). The line, the definition, is the border between an inside and an outside. On one side of the line (on the inside), there will be martial arts (proper). On the other side of the line is the outside, which is everything else, and which is not proper to martial arts. This is one way to depict the ideal, tidy, well-defined situation: On one side of the line, the inside, the proper object of martial arts studies; on the other side of the line, the outside, all the stuff that is not the object of martial arts studies.

This may seem simple. But it is not. As this book has sought to illustrate in various ways, it does not take too much time to realise that 'martial arts' cannot actually be disentangled, disambiguated or extricated from many of the things that any definition will try to say is not proper to them. Any such definition will not merely be an abstraction, it will also be a reduction and indeed therefore a fiction. It will share many of the features of a representation of something that does not actually exist anywhere. Rather than this, in the cultural world of martial arts practice and discourse, there are always supplements, images, ideas, practices, products, fantasies, realia, phantasmagoria, simulacra, prosthesis, grafts, add-ons, extras, and 'related', that cannot and will not be removed.

A dawning realisation of this ineradicable proliferation and constitutive multiplicity accounts for why people often attempt to escape from the trap by 
moving from the singular to the plural. People can often realise that there is no simple unity, but they nonetheless still want to erect a definition. Because of this, realising that the category 'martial arts' is constitutively imprecise, scholars try to return us to precision by adding categories. Accordingly, we get more categories, we get refinements and differentiations: Martial arts and/or combat sports, self-defence, military combat training, combatives, weapons-based combat systems, religious practices, cultural traditions, calisthenics taught in schools, traditional, non-traditional, deracinated, de- and re-territorialized practices, and so on and so forth. This produces ideas of entities that are called hybrids, and so on. However, each addition, seeking to introduce a level of clarity and precision, nonetheless inexorably introduces even more grey area, imprecision and further grounds for disagreement.

This occurs because the perceived need to introduce more and more terms and concepts in order to try to clarify things is a paradoxical drive that comes in response to a fundamental lack of precision and clarity. This can never fully be eradicated by trying to mop it up by throwing more categories at it. The addition of ever more categories, gradations and combinations does not actually produce clarity or reduce unclarity. Rather, it principally produces metalanguages and ever more intricate language games.

Metalanguages and language games are not somehow simply or necessarily universally true. They are themselves locally-produced cauldrons of terminological soup. When they sound scientific, they may be impressive. But they are, at root, just variable attempts to solve the problem of how to conceptualise and communicate with clarity and precision. But because there is no necessary relation between a field and its demarcation, a practice and its conceptualisation, nor indeed between one discourse and another, 'clarity and precision' only exist within a community of language game players. Stated differently, how those steeped in anthropological approaches may have long been inclined to conceptualise and demarcate 'martial arts' may differ hugely from how those working in sociology, cultural studies, philosophy, religious studies, dance or theatre studies may each have done so. Each approach involves a language game, the production of a metalanguage, and each of these is almost certainly going to differ from others.

This is a situation of proliferation, despite all attempts to pin down and wrap up. Producing proliferation, producing more, is what academic (and other) discourses do. They do not simply strip away and reveal bare or naked essentials. They construct and fabricate lenses through which to see differently. They produce alternatives. They challenge each other. They generate more.

In the field of martial arts studies, discussions often circulate around different conceptualisations of the object 'martial arts'. It is clear that different people draw the line around their conceptualisation of their object of attention differently. It is my hope that over time it should become more and more clear that the definitional act of drawing a line is inherently problematic. Which is not to say that it is not going to be done. Everyone needs to find ways to be able 
to refer, or to say 'I am talking about this, and not that'. Every academic study needs to draw the line between the inside (what it is about) and the outside (what it is not, cannot or will not be about or even look at). As I regularly say to my $\mathrm{PhD}$ students, there are two questions that every examiner will ask you in one way or another. First, why did you draw the line here and not there? And second, why did you approach it in this way and not another?

Both of these questions must be answered. You need to know that you could have drawn your line elsewhere and differently, and that this would inevitably have changed things. You also need to know that you could have approached it differently, and that this would have produced very different kinds of insight, perspective, result, outcome or conclusion. In other words, what academic works need more than some inevitably failed definition is a critical reflection on the necessary act of drawing a line - any and every 'I am talking about this (and not that) in this way (and not another way)'. Indeed, doing so enables us to see that there are more important matters than where to draw the line. These involve thinking about how and why a line has been drawn.

In conversation with a colleague who works in performance studies, for instance, my colleague voiced reluctance to work under the heading of 'martial arts studies' at all. This is because the act of drawing a line around such practices seemed not only somewhat arbitrary, stifling and artificial, in terms of his own interests, but also ethically problematic. As someone interested in performance, he asked why he would separate martial arts from other kinds of physical practice. And anyway, how and why could or would anyone really draw convincing lines between martial arts practices and dance or theatre or ritual or religion, or indeed athletics, somatics, or therapeutics, and so on?

On thinking about this, I became inclined to expand the problem further and wider. Maybe my colleague is actually still too limited - too steeped in thinking about embodied practices. For, what about media and technology? Can we separate martial arts, or the study thereof, from practices and studies of film, drama, gaming, literature, or heritage? What about philosophy?

Nonetheless, the ethical dimension of my colleague's reluctance seemed particularly thought-provoking. What does it mean to cast a net that only looks for and at martial, combative, fighting, defensive or offensive practices? What does it mean to insist on identifying all of the practices out there that seem to fit the bill in terms of their 'martial' dimensions? Is this not in and of itself a violent contortion, and a bending of the world to the will or the mind's eye of the observer? Maybe my escrima practice seems fairly obviously martially orientated. But what about my taiji practice? Just because I search in my taiji practice for combative dimensions and applications, must I insist on reducing taiji to this dimension for everyone, and enshrining it in academic discourse in this particular contingent and motivated way?

Inventing and chopping up the conceptual spectrum in such a way as to enable the claim that 'martial arts' is an obvious and necessary field, fit for an academic discipline to congregate around it, may actually seem like a fairly contorted and 
contorting act, when viewed from a broader perspective. Privileging 'martial' over 'art' may also amount to doing a kind of violence to the very objects that fall within its purview.

How can any such tendentious act be justified? Should perhaps martial arts studies really always be understood as a subset of other fields, such as performance studies, for instance? The answer could be yes. As long as it can also be agreed that it should also be a subset of religious studies, and a subset of film studies, as well as a subset of subcultural studies, ethnic studies, area studies, sports studies, history, and so on. The point is that none of these subsets exist on a fixed or immutable map. There is no Venn diagram or flow chart that could adequately depict some real or permanent relation of inclusivity or exclusivity. There is no essential or necessary 'proper place' for this or any other field. Its 'proper place' is always a consequence not of fit but of performative elaboration. This is because 'martial arts', like anything else ('literature', 'religion', 'science') is a contingent discursive establishment (a construct) rather than an essential referential category (a datum).

To evoke a Kantian distinction, 'martial arts' is synthetic rather than analytic. It is not an object proper to scientific study, and nor does it need to be. The study of something like this is not really scientific because - to borrow an insight that D.N. Rodowick once made about 'film studies' - it is something we simply know about, that we experience in different ways at different times and in different places, something that changes, that changes us, that we can change, and so on (Rodowick 2007; see also Rodowick 2014). We can't really 'do' martial arts studies exhaustively or thoroughly, as if it were some kind of science. It doesn't lend itself to that kind of treatment at all. Rather, it presents itself as a range of phenomena for reflection, philosophy, theory, rumination. Martial arts, however conceived or however instantiated, seem or seems to beg questions questions about 'what it is' and about 'other things': Life, value, health, gender, nation, strength, honour, fun, commerce, ethnicity, culture, identity, and more.

To choose martial arts studies as a category - to attempt to institute it as a field - is to accept or at least trade in an inheritance. We have the term 'martial arts'. It is a discursive category, even if it is not properly referential, indeed even if it is barely able to evoke its own content. Nonetheless, history has given it to us. People are likely to 'kind of just know' what you mean when you say it, even if their understandings are hugely different, even utterly incompatible, and even though any attempt to specify the content of the field cannot but produce contradictory objects and practices. This is the most 'obvious' reason I avoided the so-called problem of definition for so long: Because one 'obviously' need not define because 'obviously', 'in the real world', definition is a pseudoproblem - the effect of a certain orientation in the face of what it means to study or do academic work.

Of course, one always has to negotiate competing injunctions. Definitions and categories do emerge. But they often fall down when pressed or pushed. Such definitions need to be pressed or pushed and pulled, because they can 
come to seem stifling. And they can come to be stifling - because of the effects that they can have on our orientations.

This is why I argue that, in martial arts studies as elsewhere, the question should not simply be 'Where do you draw the line?' Rather, the equally perhaps more - important questions that we should engage with are 'Why draw a line?' and indeed 'How can we let ourselves try to draw a line?' If one feels compelled to draw a line around a field or object, and to map it out in a certain way, this is a compulsion one might expect to be matched with an equal compulsion when it comes to policing the territory that has been marked out. In other words, those scholars who seem merely to be exercising an honest and innocent drive to speak clearly and precisely and to define coherently may yet turn out to be the most diligent border guards, hostile to any non-legitimate travellers.

The postcolonial critic Gayatri Spivak once argued that making any distinction, making any discrimination, specifying, erecting or using any conceptual categories, is irreducibly and inescapably political in some sense. This is because producing differentials erects binaries, and binaries are inevitably hierarchical. The inside is the proper, the outside is the improper, the other. The question thus becomes: How hospitable are we to be to difference that presents itself as impropriety, as alterity? How is difference to be treated? This is both the ethicopolitical and conceptual-orientation problem of all disciplinary discourse. For martial arts studies, it suggests that what needs to be asked is: How do we define the hospitality of martial arts studies to that which requests admittance but seems improper? How do we invent both martial arts and martial arts studies in our discourse? Engaging such important questions relies on deconstruction the deconstruction both of martial arts and of martial arts studies. 